\title{
Liste der befragten Unternehmerinnen und Unternehmer
}

Die Unternehmer wurden nach ihrer herkunftsmäßigen Selbstzuschreibung gefragt. Diese ist bei den BKS-Migranten, falls vorhanden, zur Information angeführt.

\section{Nr. Branche}

T 1 Gastronom, Cafes und Restaurants mit 19 Filialen

T 2 Gastronom, Cafe und Bar

T 3 Inhaberin einer Parfümerie

T 4 Taxiunternehmer

T 5 Friseurin

T 6 Bauunternehmer

T 7 Barbesitzer

T 8 Inhaberin eines Reisebüros

T 9 Großhändler mit Obst und Gemüse

T 10 Inhaber eines Malerbetrieb

T 11 Gastronom, Schnitzelhaus

T 12 Inhaberin eines Taschengeschäfts

T 13 Inhaber einer Shisha-Bar

$\mathrm{T} 14$

$\mathrm{T} 15$

BKS 1

BKS 2

BKS 3

BKS 4

BKS 5

BKS 6

BKS

BKS 8

BKS 9

BKS 10 Inhaber Überwachungs- und Sicherheitsdienst, Serbe

BKS 11 Friseur, Bosnier

BKS 12 Bauunternehmer, Bosnier

BKS 13 Bodenleger, Serbe

BKS 14 Taxiunternehmer, Serbo-Kroate

BKS 15 Gastronom, Serbe
Zahl der Mitarbeiter 